\title{
Removal of Hexavalent Chromium Using Activated Carbon Prepared from Teak Wood Waste Biomass
}

\author{
G. Vijayalakshmi*, B. Ramkumar \\ PG \& Research Department of Chemistry, Government Arts College, Tiruchurappalli -620022, Tamil Nadu, India
}

\begin{abstract}
The present work reported the adsorption of $\mathrm{Cr}$ (VI) from aqueous solutions on activated carbon prepared from teak wood waste. Biomass from teak wood were taken out and pulverized in a micro-pulverizing mill. The powder thus obtained was activated with $40 \% \mathrm{H}_{3} \mathrm{PO}{ }_{4}$ and carbonized at $600{ }^{\circ} \mathrm{C}$ for 1 hour in an inert atmosphere. Physico-chemical characteristics such as functional groups and surface morphology of the activated carbon were analyzed using FTIR spectroscopy and SEM analysis respectively. Batch adsorption experiments were performed to investigate the effects of $\mathrm{Cr}$ (VI) concentration, carbon dose, $\mathrm{pH}$ and time. The maximum adsorption capacity of Cr(VI) was found to be $1.5 \mathrm{~g} / \mathrm{L}$ at $\mathrm{pH} 3$ and temperature $30 \pm 1{ }^{\circ} \mathrm{C}$. The Freundlich adsorption isotherm best represented the equilibrium data and a pseudo-second order relation represented the adsorption kinetics.
\end{abstract}

Keywords: Activated carbon, Cr(VI) removal, SEM, kinetics, adsorption isotherms

Article Info: Received 28 June 2019; $\quad$ Review Completed 20 Aug 2019; $\quad$ Accepted 29 Aug 2019; Available online 15 Sep 2019

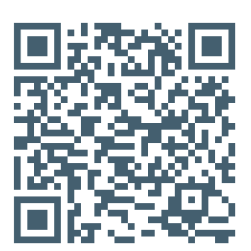

Cite this article as:

Vijayalakshmi G, Ramkumar B, Removal of Hexavalent Chromium Using Activated Carbon Prepared from Teak Wood Waste Biomass, Journal of Drug Delivery and Therapeutics. 2019; 9(5):51-55 http://dx.doi.org/10.22270/jddt.v9i5.3307

*Address for Correspondence:

G. Vijayalakshmi, PG \& Research Department of Chemistry, Government Arts College, Tiruchurappalli -620022, Tamil

Nadu , India.

\section{INTRODUCTION}

The release of heavy metals into wastewater through human and industrial activities has become a major problem both to humans and aquatic lives ${ }^{1}$. Chromium as a heavy metal is ranked among the top sixteen toxic pollutants that have harmful effects on human health ${ }^{2}$. High chromium dosage has been reported to cause damage to human kidney and the liver ${ }^{3}$; and at low concentration it causes skin irritation and ulceration 4 . Exposure to high chromium concentration also causes cancer in the digestive tract and lungs ${ }^{5}$. Therefore, indiscriminate discharge of heavy metals in general into aquatic bodies and sources of potable water has to be regulated through enactment of legal standards and strict environmental control mechanism ${ }^{6}$. For the removal of dissolved heavy metal ions, several techniques such as solvent extraction, ion exchange, membrane process, electro dialysis, precipitation, phyto extraction, ultra filtration, reverse osmosis and adsorption have been tested. These methods except adsorption are non-economical with disadvantages such as incomplete metal removal, high reagent cost, energy requirements and generation of toxic sludge or other waste products that require further disposal or treatment. The adsorption technique remains the most preferred method because of its efficiency and low cost ${ }^{7}$.

Many investigations have been carried out on the effective removal of heavy metals from solution using natural adsorbents derived from agricultural wastes ${ }^{8}$. The present study is therefore carried out to investigate the possible use of teak wood waste material, for the removal of chromium ions from aqueous solution. The effects of some parameters such as, contact time, solution $\mathrm{pH}$, adsorbent dose and initial chromium ions concentrations on the performance of the adsorbent on the sorption process were investigated. Scanning electron microscopy (SEM) and Fourier transform infrared spectroscopy (FTIR) were used to analyze the possible mechanism of the adsorption process. The equilibrium data were analyzed using Langmuir and Freundlich isotherm models.

\section{MATERIALS AND METHODS}

Adsorbents: The teak wood waste biomass material was collected and air dried for 15-20 days. The dried material was cut into small pieces for further chemical modification. The ground material was mixed with equal amount of concentrated phosphoric acid and stirred for $30 \mathrm{~min}$. The acid- plant material slurry was placed in a beaker and dried at $80{ }^{\circ} \mathrm{C}$ in a hot air-oven. After $24 \mathrm{~h}$, the thermo chemical reaction between acid and plant materials, it was proceeding by raising the oven temperature to $120{ }^{\circ} \mathrm{C}$ for $90 \mathrm{~min}$. After cooling, the resulting carbon washed with distilled water until a constant $\mathrm{pH}$ of the slurry reached. The wet carbon material was dried at $110{ }^{\circ} \mathrm{C}$ and sieved into discrete particle size and stored. The adsorbent after phosphoric acid treatment was designated as TPAC. All the chemicals used throughout the study were supplied by so fine chemicals, 
E.Merck, India. All the adsorption experiments were carried out at room temperature $\left(30 \pm 1^{\circ} \mathrm{C}\right)$.

Adsorbate: A stock solution of $\mathrm{Cr}(\mathrm{VI})$ was prepared (1000 $\mathrm{mg} / \mathrm{L}$ ) by dissolving required amount of Potassium dichromate salt, $\mathrm{K}_{2} \mathrm{Cr}_{2} \mathrm{O}_{7}$ in distilled water. The stock solution was further diluted to obtain desired concentration ranging from 20 to $100 \mathrm{mg} / \mathrm{L}$.

Batch experiments: Batch equilibrium experiments were conducted by adding $100 \mathrm{mg}$ biomass to Erlenmeyer flask containing $50 \mathrm{ml}$ of different test solutions at desired $\mathrm{pH}$ conditions. The initial solution $\mathrm{pH}$ was adjusted by using 0.1 $\mathrm{M} \mathrm{HCl}$ or $0.1 \mathrm{M} \mathrm{NaOH}$. The flasks were agitated at $150 \mathrm{rpm}$ in a rotary shaker. After 3 hrs of contact time, the biomass was separated from the test solution by filtration. The chromium ion content in the supernatant liquid was determined using photoelectric calorimeter. Prior to analysis, the equipment was initially calibrated using standard chromium ion solution. The amount of chromium ion adsorbed by biomass was calculated from the difference between the concentration of chromium ion in test solution and the concentration of chromium ion in the supernatant liquid. The amount of adsorption at equilibrium $\left(\mathrm{q}_{\mathrm{e}} \mathrm{mg} / \mathrm{g}\right)$ and sorption efficiency (\%) were calculated according to the expressions:

$\mathrm{q}_{\mathrm{e}}(\mathrm{mg} / \mathrm{g})=\left(\mathrm{C}_{\mathrm{o}}-\mathrm{C}_{\mathrm{e}}\right) \mathrm{V} / \mathrm{m}$
Where $\mathrm{C}_{0}$ and $\mathrm{C}_{\mathrm{e}}$ are the initial and equilibrium concentrations (mg/L), V the volume of solution (L), $\mathrm{m}$ is the mass of the activated carbon (g).

\section{RESULTS AND DISCUSSION}

\section{FTIR analysis of activated carbon}

The surface chemical characteristics of TPAC were determined by Fourier Transform Infrared Spectroscopy (FTIR), and the spectrum is given in Fig. 1. The peak at $3407 \mathrm{~cm}^{-1}$ is attributed to the stretching vibration of $\mathrm{O}-\mathrm{H}$ band and aliphatic, asymmetric $\mathrm{C}-\mathrm{H}$ stretching vibration of methylene group 9 . The peaks at $2924 \mathrm{~cm}^{-1}$ in the spectra are due to stretching vibration of $\mathrm{C}-\mathrm{H}$. The band at 1750 $1700 \mathrm{~cm}-1$ represents the acidic carbonyl $\mathrm{C}=0$ stretching. The peak at $1707 \mathrm{~cm}-1$ is attributed to the vibration of $\mathrm{COOH}$ band ${ }^{10,11}$. The peaks around 1000$1300 \mathrm{~cm}-1$ presents $\mathrm{C}-\mathrm{O}$ stretching in phenols, alcohols, acids, ethers and esters. These groups participate in $\mathrm{Cr}(\mathrm{VI})$ adsorption to TPAC. The surface of carbon materials is, in general, rich in a variety of surface functional groups among which the $\mathrm{C}-\mathrm{O}$ type groups are predominant and they form in ethers, acids and esters. FTIR analysis confirmed the presence of carboxylic and phenolic surface groups on the TPAC. There are hydroxyl groups $\left(3407 \mathrm{~cm}^{-1} ; 0-\mathrm{O}\right.$ stretching mode) present in the IR spectrum of the functionalized TPAC (see Fig. 1).

Sorption efficiency $\%=\left[\left(\mathrm{C}_{o}-\mathrm{C}_{\mathrm{e}}\right) / \mathrm{C}_{\mathrm{o}}\right] \mathrm{X} 100$

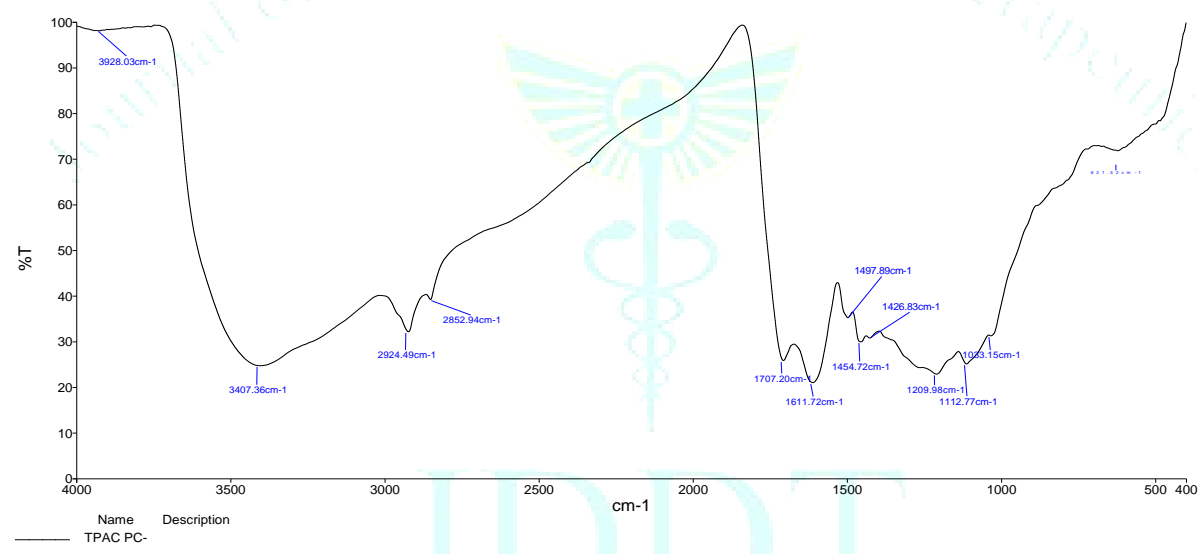

Fig.1: IR spectrum of activated carbon TPAC

The SEM micrograph of TPAC before adsorption is shown in Fig. 2. It is seen that TPAC has a highly porous structure.

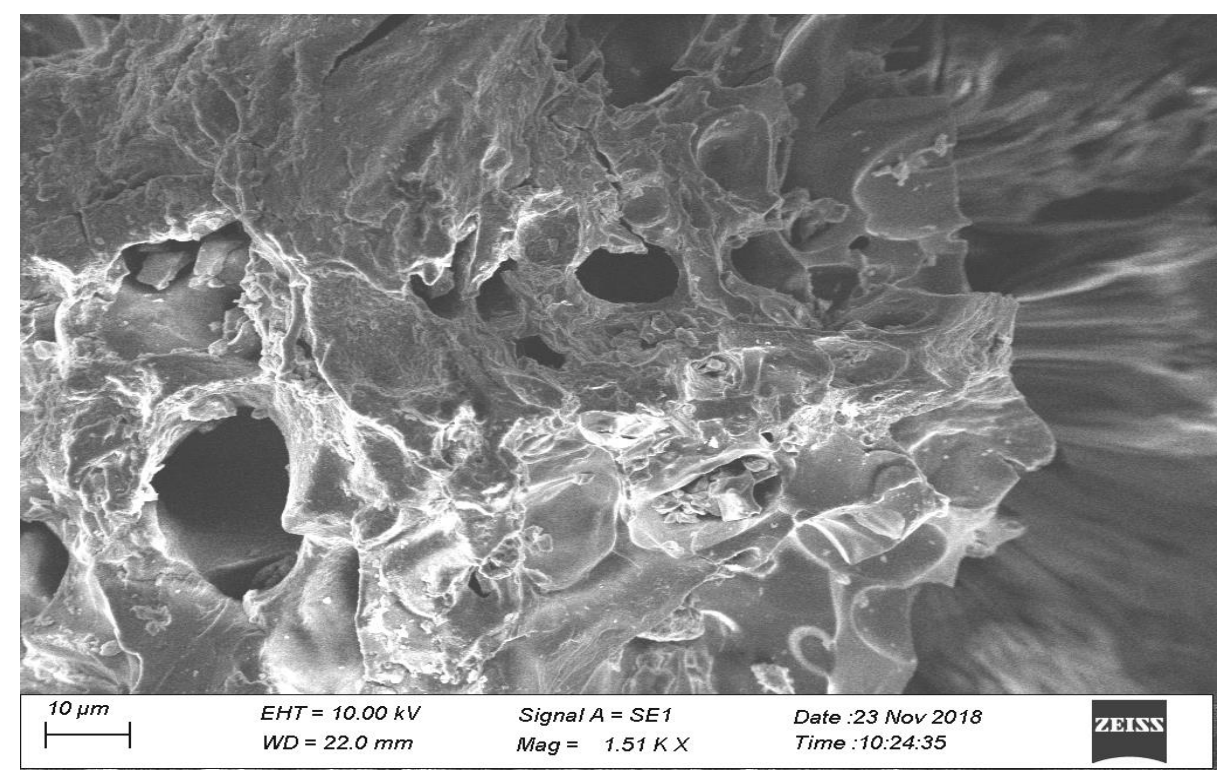

Fig.2: SEM image of TPAC 


\section{Effect of $\mathrm{pH}$}

About $50 \mathrm{ml}$ of $50 \mathrm{ppm}$ chromium aqueous solutions were prepared and the $\mathrm{pH}$ were adjusted by using $0.1 \mathrm{M} \mathrm{HCl} / 0.1$ $\mathrm{M} \mathrm{NaOH}$. Each solution was treated with $100 \mathrm{mg}$ of the adsorbent and kept for a contact time of 3 hours at room temperature with intermittent shaking. The residual chromium ion concentrations were measured. Maximum adsorption occurred at $92.0 \%$ at pH 3 (Fig.3) and the reasons were as follows: Analysis from the perspective of adsorbate: in aqueous solution, $\mathrm{Cr}$ (VI) mainly exists in three forms ${ }^{12}$ of $\mathrm{CrO}_{4}^{2-}, \mathrm{Cr}_{2} \mathrm{O}_{7}^{2-}$ and $\mathrm{HCrO}_{4}$. With the change of solution $\mathrm{pH}$, the form of will change accordingly. When the solution is acidic, $\mathrm{Cr}$ (VI) is mainly distributed in the form of $\mathrm{HCrO}_{4}^{-}$, the study found that $\mathrm{HCrO}_{4}^{-}$can form stable compounds with adsorbent. In the acidic conditions, the oxidation of $\mathrm{Cr}(\mathrm{VI})$ is very strong, the oxidation and reduction on the removal of $\mathrm{Cr}(\mathrm{VI})$ to make a contribution. Therefore, the removal rate is high under acidic conditions. When the $\mathrm{pH}$ of the solution increases gradually, the $\mathrm{Cr}$ (VI) in the solution begins to be dominated by $\mathrm{CrO}_{4}{ }^{2-}$ and $\mathrm{Cr}_{2} \mathrm{O}_{7}^{2-}$; With the concentration of $\mathrm{OH}^{-}$increases, and the competitive adsorption of with $\mathrm{Cr}$ (VI) results in inhibition of the adsorption of $\mathrm{Cr}(\mathrm{VI})$. So under acidic conditions, the removal rate of $\mathrm{Cr}(\mathrm{VI})$ is higher than that under alkaline condition.

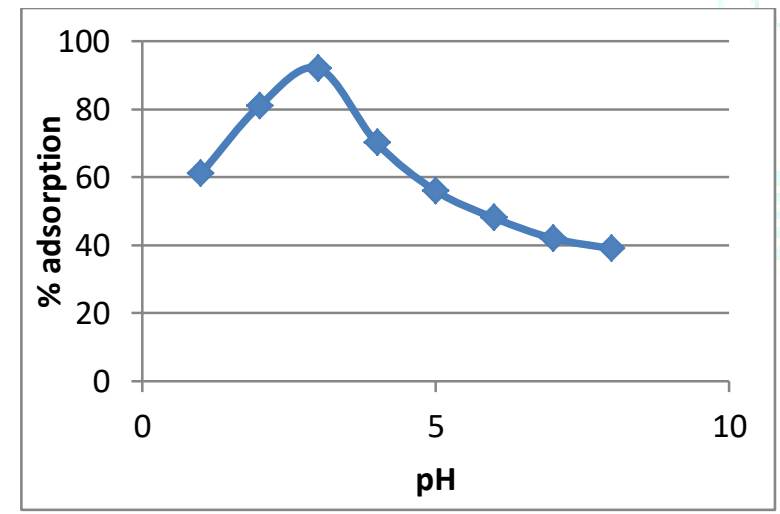

Fig.3: Effect of pH on removal of Chormium using TPAC; Initial con-50mg/l; Time : 3 hrs; Wt. of adsorbent - 100 mg; Temp $=30^{\circ} \mathrm{C} \pm 1$

\section{Effect of Activated Carbon Dosage on Adsorption of $\mathrm{Cr}$} (VI)

The dosages of activated carbon respectively are $0.2 \mathrm{~g}, 0.6 \mathrm{~g}$, $1.0 \mathrm{~g}, 1.5 \mathrm{~g}, 2.0 \mathrm{~g}$ and $2.5 \mathrm{~g}$; The concentration of $\mathrm{Cr}$ (VI) solution is $10 \mathrm{mg} / \mathrm{L}$; the temperature is at room temperature; the adsorption time is $120 \mathrm{~min}$; the solution $\mathrm{pH}$ is 3. The effect of activated carbon dosage on removal of $\mathrm{Cr}$ (VI) is shown in Fig.4. In the picture, it can be seen that when the activated carbon dosage increased from $0.2 \mathrm{~g}$ to $2.5 \mathrm{~g}$, the removal rate of $\mathrm{Cr}$ (VI) increased from $15.86 \%$ to $96.46 \%$, showed a rising trend. Analysts believe that with the increase of the amount of activated carbon, the available adsorption sites in the contact reaction increased correspondingly. The amount of $\mathrm{Cr}$ (VI) adsorbed by activated carbon increased, which showed that the removal rate increased with the increase of dosage . It is also found that the amount of adsorption decreases with the increase of dosage. The reason is that the dosage increases and the specific surface area increases, so more $\mathrm{Cr}$ (VI) is adsorbed on the surface of activated carbon, but the unit surface utilization of adsorbent decreases. Thus, the amount of activated carbon is not the more the better. From the above analysis, $1.5 \mathrm{~g} / \mathrm{L}$ was selected as the best dosage for removing of $\mathrm{Cr}$ (VI).

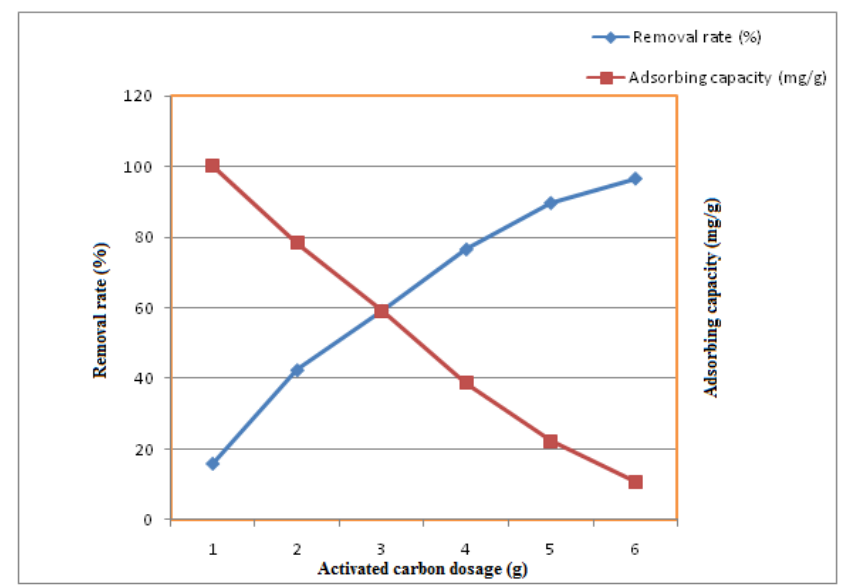

Fig.4: The effect of activated carbon dosage on removal of Cr (VI)

\section{Initial Concentration}

To $50 \mathrm{ml}$ solutions of each 10 to $50 \mathrm{ppm}$ of chormium ion solution, $100 \mathrm{mg}$ of TPAC powder was added and left for a period of 3 hours at room temperature $\left(30 \pm 1^{\circ} \mathrm{C}\right)$ with intermittent shaking. Appropriate control flasks without adsorbent were also maintained. The results of adsorption were recorded to calibrate the equilibrium time. The effect of initial concentration on the removal of chromium ion shown in Fig.5.

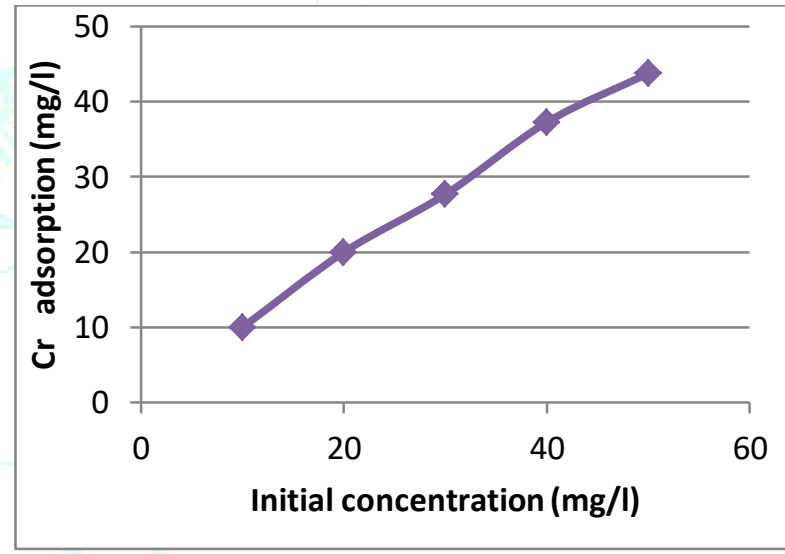

Fig. 5: Effect of Initial concentration on removal of chromium using TPAC ( $\mathrm{pH}=3)$

\section{Effect of Contact Time}

As shown in Fig.6, the extent adsorption increases steeply with increasing contact time and tends to a constant value. In the beginning all the active sites on the adsorbent are vacant hence adsorption proceeds at a faster rate and desorption at a lower rate, the net effect is faster increase in the extent of adsorption. As the active sites get occupied, the rates of adsorption and desorption tend to be equal and extent of adsorption reduces and eventually becomes nearly constant at equilibrium. Any further adsorption beyond this is through intra-particle diffusion which is a much slower process 13,14 . For the given situation adsorption equilibrium time is observed to be $150 \mathrm{~min}$. 


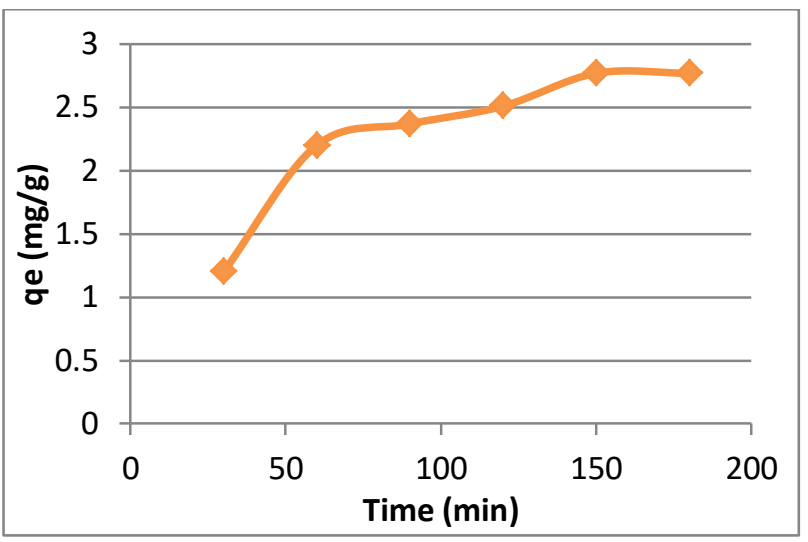

Fig.6: Effect of contact time on removal of chromium using TPAC ( $\mathbf{p H}=3$; Wt. of adsorbent $=100 \mathrm{mg}$; Initial concentration : $30 \mathrm{mg} / \mathrm{l}$; $\mathrm{Temp}=30 \pm 1^{\circ} \mathrm{C}$ )

\section{Adsorption isotherm studies}

For solid-liquid adsorption system, the adsorption behavior can well be described by adsorption isotherm model ${ }^{15}$ [15]. The adsorption isotherm can indicate the distribution of adsorbate molecules between the solid phase and the liquid phase at equilibrium. Equilibrium is said to be established when the concentration of adsorbate in bulk solution is in dynamic balance with that on the liquid adsorbate interface. It is significant to understand the adsorption behavior in order to describe adsorption process using appropriate adsorption isotherm model. Therefore, the distribution of $\mathrm{Cr}(\mathrm{VI})$ ions between the adsorbent and solution was determined by Langmuir and Freundlich adsorption isotherms by fitting the equilibrium adsorption data into their respective isotherm equations ${ }^{16,17}$.

\section{Freundlich adsorption isotherm}

The Freundlich equilibrium isotherm model describes adsorption by heterogeneous energetic distribution of adsorption sites accompanied by interaction between solute molecules (Eq. 3).

Freundlich equation:

$$
\left(\frac{x}{m}\right)=k C_{e}^{1 / n}
$$

where $\mathrm{n}$ is the Freundlich constant and $\mathrm{k}$ is adsorption coefficient, $\mathrm{x} / \mathrm{m}$ is the amount of $\mathrm{Cr}(\mathrm{VI})$ ions adsorbed per unit amount of adsorbent and $\mathrm{C}$ e is $\mathrm{Cr}(\mathrm{VI})$ concentration at equilibrium in aqueous phase. Logarithmic form of eqn (3) as follows:

$$
\begin{aligned}
& \log \left(\frac{x}{m}\right)=\log k+\frac{1}{n} \log C_{e} \\
& \log q_{e}=\log k+\frac{1}{n} \log C_{e}
\end{aligned}
$$

Where $\mathrm{x} / \mathrm{m}=\mathrm{q}_{\mathrm{e}}$. The Freundlich isotherm and the Langmuir isotherm apply to TPAC adsorbate system. The isotherm giving an $\mathrm{R}^{2}$ value closest to unity was deemed to provide the best fit. The Freundlich model has contained two useful parameters $(\mathrm{k} \text { and } \mathrm{n})^{18,19}$.

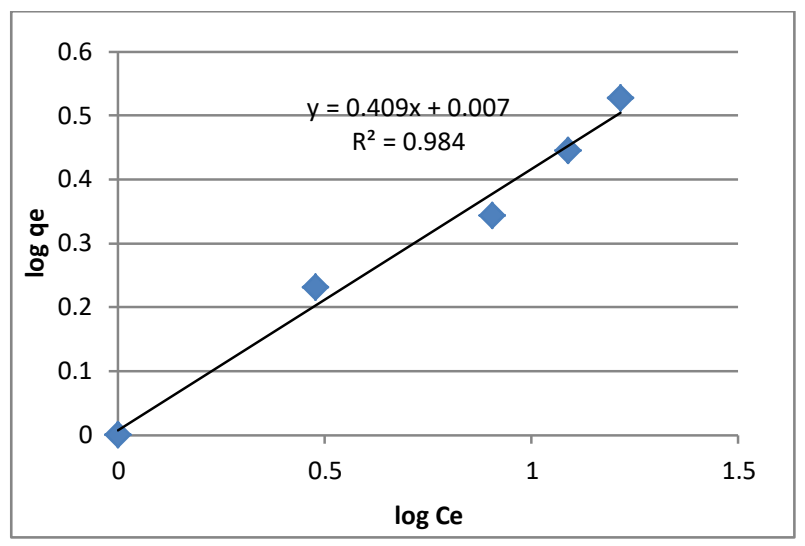

Fig.7: Freundlich plot

\section{Langmuir adsorption isotherm}

The equilibrium adsorption data for the concentrations of $\mathrm{Cr}(\mathrm{VI})$ ions was fitted into the linear form of Langmuir's isotherm equation(6) to determined the distribution of $\mathrm{Cr}(\mathrm{VI})$ ions between the adsorbent and solution:

$$
\frac{c_{e}}{q_{e}}=\frac{1}{q_{0} b}+\frac{c_{e}}{q_{e}}
$$

Where Ce is the equilibrium concentration of the chromium ions in solution $(\mathrm{mg} / \mathrm{L}), \mathrm{q}_{\mathrm{e}}$ is the equilibrium concentration of $\mathrm{Cr}(\mathrm{VI})$ ions on the TPAC adsorbent $(\mathrm{mg} / \mathrm{g})$, $\mathrm{q}_{0}$ and $\mathrm{b}$ are Langmuir constants related to sorption capacity and the rate of adsorption respectively.

Maximum adsorption capacity $\left(\mathrm{q}_{0}\right)$ is the monolayer capacity of the adsorbent (mg/g) and $b$ is the Langmuir adsorption constant. A plot of $\mathrm{Ce} / \mathrm{qe}$ against $\mathrm{Ce}$ over the entire concentration range is a straight line with a slope of $1 / q_{0}$ and the intercept of $1 / q_{0} b$.The correlation coefficient $\left(R^{2}\right)$ value is 0.978 .

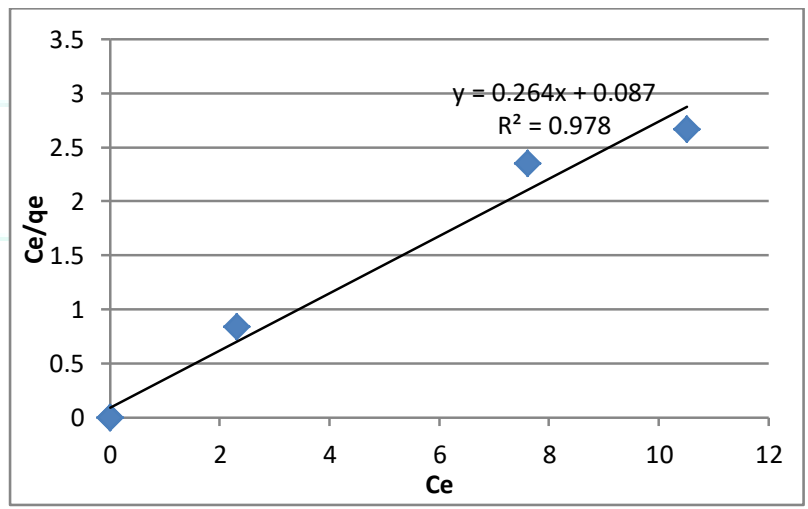

Fig. 8: Langmuir isotherm ( $\mathrm{pH}=3$; Particle size : 0-63 $\mu$; Wt. of adsorbent $=100 \mathrm{mg}$; Time : 150 minutes ; Temp $=30 \pm 1^{\circ} \mathrm{C}$ )

Among the Freundlich and langmuir model studied, the correlation coefficient $\left(\mathrm{R}^{2}\right)$ value is 0.984 which is very close to 1 indicating that the adsorption follows the Freundlich isotherm

\section{Kinetic study}

The kinetics of $\mathrm{Cr}(\mathrm{VI})$ sorption on the TPAC activated carbon as adsorbent was analyzed using two kinetic models. The linearized form of pseudo-first-order kinetic model ${ }^{20}$ and the pseudo-second-order sorption kinetics can be expressed as shown in Fig.9 and Fig.10. and show the plots of experimental data at different initial concentration of $\mathrm{Cr}(\mathrm{VI})$ for pseudo-first order and second order, models, 
respectively. The calculated kinetic parameters are presented in Table. Closure agreement between experimental and calculated kinetic constants and coefficient of correlation closure to unity indicated that the pseudo second order model better represents the experimental data.

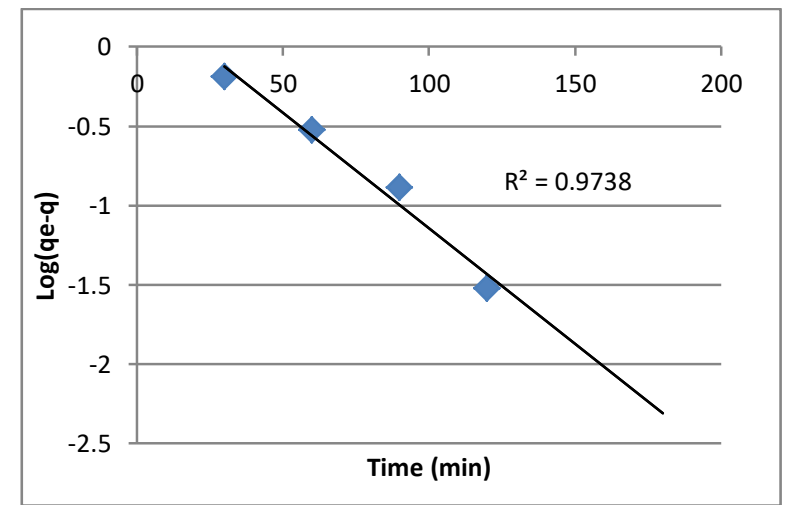

Fig. 9: Pseudo first-order plot for the adsorption of $\mathrm{Cr}$ (VI) by activated TPAC for adsorbent dosage $20 \mathrm{mg} /$ lit and concentration $100 \mathrm{mg} / \mathrm{lit}$

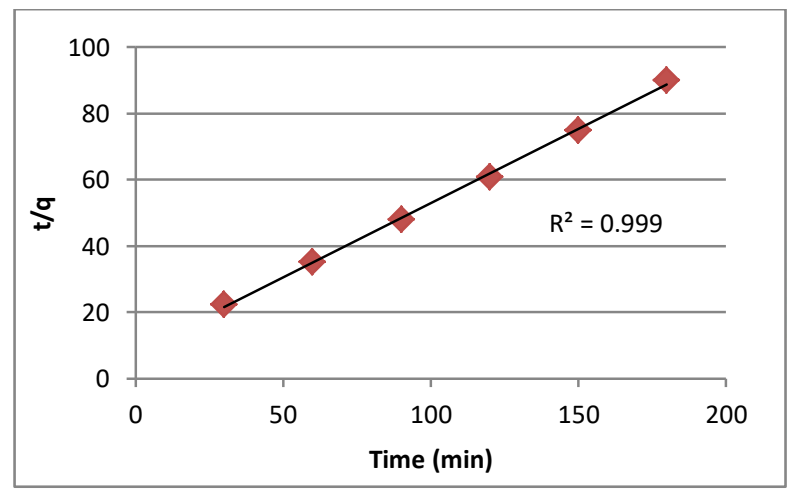

Fig.10: Pseudo-second-order kinetic model for removal of $\mathrm{Cr}$ (VI) by TPAC (Solution pH: 3; Wt. of adsorbent = $100 \mathrm{mg}$; Initial concentration : $10 \mathrm{mg} / \mathrm{l} \mathrm{Temp}=30 \pm 1^{\circ} \mathrm{C}$ ).

\section{CONCLUSION}

The results indicate that the teak wood biomass activated carbon is a good sorbent. The adsorption of $\mathrm{Cr}(\mathrm{VI})$ was found to be highly dependent on the $\mathrm{pH}$ value of the system, with the best results being obtained at $\mathrm{pH} 3$. A high percentage of $\mathrm{Cr}(\mathrm{VI})$ may be reduced to the $\mathrm{Cr}$ (III) form at low $\mathrm{pH}$ values. The FTIR spectra showed that the hydroxyl group was the chromium binding site within the $\mathrm{pH}$ range (pH 1-4) where chromium does not precipitate. Chromium (VI) was rapidly adsorbed when lower concentrations were used. The isotherm data were analyzed by the Langmuir and Freundlich isotherms and the data fitted Freundlich model better than the Langmuir isotherm model. The kinetic data were well fitted by a pseudo-second order model.

\section{REFERENCES}

[1] Wang Q, Song J, Sui M. Characteristic of adsorption, desorption and oxidation of $\mathrm{Cr}(\mathrm{III})$ on birnessite. Energy Procedia, 2011;5:1104-8.
[2] Gardea-Torresday JL, Tiemann KJ, Armendariz V, Bess-Oberto L, Chianelli RR, Rios J, Parsons JG, Gamez G, Characterization of $\mathrm{Cr}(\mathrm{VI})$ binding and reduction to $\mathrm{Cr}$ (III) by the agricultural by products of Avena monida(Oat) biomass, Journal of Hazardous Materials, 2000;80(1-3):175-88.

[3] Mungasavalli DP, Viraraghavan T, Jin Y-C. Biosorption of chromium from aqueous solution by pretreated Aspergillus niger: batch and column studies. Colloids and Surfaces A: Physicochemical and Engineering Aspects, 2007;301(1-3):21423.

[4] Karthikeyan T, Rajgopal S, Miranda LS. Chronium(VI) adsorption from aqueous solution by Hevea Brasilinesis saw dust activated carbon. Journal of Hazardous Materials, 2005;124(1-3):192-9.

[5] Ofudje EA, Awotula AO, Oladipo GO, Williams OD. Detoxification of chromium(VI) ions in aqueous solution via adsorption by raw and activated Carbon prepared from sugarcane waste. Covenant Journal of Physical and Life Sciences, 2014;2(2):110-22.

[6] Garg VK, Gupta R, Kumar R, Gupta RK. Adsorption of chromium from aqueous solution on treated sawdust. Bioresource Technology, 2004;92(1):79-81.

[7] Li Q, Zhai J, Zhang W, Wang M, Zhou J. Kinetic studies of adsorption of $\mathrm{Pb}(\mathrm{II}), \mathrm{Cr}$ (III) and $\mathrm{Cu}(\mathrm{II})$ from aqueous solution by sawdust and modified peanut husk. Journal of Hazardous Materials, 2007;144(1-2):163-7.

[8] Sarin V, Pant KK. Removal of chromium from industrial waste by using eucalyptus bark. Bioresource Technology, 2006;97(1):1520.

[9] Zhang S, Zeng M, Xu W, Li J, Li J, Xu J, Wang X, Polyaniline nanorods dotted on graphene oxide nanosheets as anovel super adsorbent for Cr(VI). Dalton Transactions, 2013;42(22):78547858.

[10] Hua, Chena C, Zhub X, Wanga X, Removal of chromium from aqueous solution by using oxidized multiwalled carbon nanotubes. Journal of Hazardous Materials, 2009;162(2-3), $1542-1550$

[11] Atieh MA, Removal of chromium (VI) from polluted water using carbon nanotube supported with activated carbon. Procedia Environmental Sciences, 2011;4, 281-293.

[12] Yang J, Li C, Yang B, Kang S and Zhang Z. Study on Adsorption of Chromium (VI) by Activated Carbon from Cassava Sludge. IOP Conf. Series: Earth and Environmental Science 128(2018) 012017 doi :10.1088/1755-1315/128/1/012017.

[13] S. Rangabhashiyam, N. Selvaraju, Efficacy of unmodified and chemically modified Swietenia mahagoni shells for the removal of hexavalent chromium from simulated wastewater, Journal of Molecular Liquids, 2015;209, 487-497.

[14] Bayazit, O. Kerkez, Hexavalent chromium adsorption on superparamagnetic multi-wall carbon nanotubes and activated carbon composites, Chemical Engineering Research and Design, 2014;92, 2725-2733.

[15] Tella AC, Owalude SO, Ojekanmi CA, Oluwafemi OS, Synthesis of copper-isonicotinate metal-organic frameworks simply by mixing solid reactants and investigation of their adsorptive properties for the removal of the fluorescein dye. New Journal of Chemistry, 2014;38:4494-500.

[16] Freundlich HMF. Over the adsorption in solution. The Journal of Physical Chemistry,1960; 57:385-471.

[17] Langmuir I. The adsorption of gases on plane surfaces of glass, mica and platinum. Journal of the American Chemical Society, 1918;40:1361-403.

[18] Pehlivan E, Tran HT, Ouédraogo WIK, Schmidt C, Zachmann D, Bahadir M, Removal of As(V) from aqueous solutions by iron coated rice husk. Fuel Processing Technology, 2013; 106:511517.

[19] Pehlivan E, Kahraman H, Pehlivan E, Sorption equilibrium of $\mathrm{Cr}$ (VI) ions on oak wood charcoal (Carbo Ligni) and charcoal ash as low-cost adsorbents. Fuel Processing Technology, 2011; 92, 65-70.

[20] Lagergren S. About the theory of so-called adsorption of soluble substance, Kungliga Svenska Vetenskapsakademiens, Handlingar, 1898;24, 1-39. 